\title{
Benefits of laboratory personalized antiplatelet therapy in patients undergoing percutaneous coronary intervention: A meta-analysis of randomized controlled trials
}

\author{
Yong Zhang, 2,3, Pei Zhang ${ }^{1,2}$, Zhan $\mathrm{Li}^{1,2}$, Juanjuan $\mathrm{Du}^{1,2}$, \\ Jiangrong Wang ${ }^{1}$, Xiuqing Tian ${ }^{1}$, Mei Gao ${ }^{1}$, Yinglong Hou ${ }^{1}$ \\ ${ }^{1}$ Department of Cardiology, Shandong Provincial Qianfoshan \\ Hospital Affiliated to Shandong University, China \\ ${ }^{2}$ School of Medicine, Shandong University, Jinan City, China \\ ${ }^{3}$ Department of Integrative Biology and Physiology, University of California, Los Angeles, United States
}

\begin{abstract}
Background: The preventive effects of laboratory personalized antiplatelet therapy (PAPT) strategy including genetic detection and platelet function testing (PFT) on major adverse cardiac events (MACEs) and bleeding events in coronary artery disease $(C A D)$ patients undergoing stenting has been extensively studied. Despite that, no clear conclusion can be drawn. In this study, a meta-analysis was performed to explore a more precise estimation of the benefits of laboratory PAPT.

Methods: Randomized controlled trials were identified by the use of search databases such as PubMed, Embase, and Cochrane Controlled Trials Register up to May 2017, and the estimates were pooled.

Results: Fourteen studies including 9497 patients met the inclusion criteria. The laboratory PAPT reduced MACEs risk (risk ratio $[R R] 0.58,95 \%$ confidence interval $[C I] 0.42-0.80, p=0.001$ ), stent thrombosis (RR 0.60, 95\% CI 0.41-0.87, $p=0.008$ ) and myocardial infarctions (RR 0.43, $95 \%$ CI 0.21-0.88, $p=0.02$ ) compared to the non-PAPT group. No statistically significant difference was observed between the two groups regarding cardiovascular death (RR 0.77, 95\% CI 0.51-1.16, $p=0.21)$, bleeding events (RR 0.96, 95\% CI 0.81-1.13, $p=0.59)$ and ischemic stroke (RR 0.81; 95\% $C I 0.39-1.66, p=0.57)$. The preventive effect on MACEs was more significant in patients with high on-treatment platelet reactivity (RR 0.46; 95\% CI 0.27-0.80, $p=0.006$ ).

Conclusions: Coronary artery disease patients after stenting could obtain benefits from laboratory PAPT. (Cardiol J 2018; 25, 1: 128-141)
\end{abstract}

Key words: personalized antiplatelet therapy, percutaneous coronary intervention, platelet function testing, genetic detection, meta-analysis

\section{Introduction}

Dual antiplatelet therapy consists of P2Y12 receptor antagonist such as clopidogrel, prasugrel, or ticagrelor, in combination with aspirin. This therapy represents the main medical treatment in patients with acute coronary syndrome (ACS) after percutaneous coronary intervention (PCI), and in secondary prevention of atherothrombotic events $[1,2]$. 
Among them, clopidogrel used to be the most broadly prescribed P2Y12 receptor inhibitor with undisputable benefits especially in combination with aspirin. However, since 2003, studies suggested that the pharmacodynamic effect of clopidogrel considerably varies among individuals, implying that it may lead to the occurrence of ischemic or bleeding events $[3,4]$. These events were once known as clopidogrel resistance, or clopidogrel non-responsiveness, and they are now identified as high on-treatment platelet reactivity (HTPR). Up to $25-50 \%$ of patients treated with clopidogrel show inadequate pharmacological response and a consequent inadequate protection from major adverse cardiac events (MACEs) [5, 6]. The meta-analysis performed by Sofi et al. [7] revealed a significant association between residual platelet reactivity under clopidogrel treatment and recurrent cardiovascular events. Thus, in order to improve the antiplatelet effect of clopidogrel, personalized antiplatelet therapy (PAPT) is increasingly more important.

In clinical practice, some laboratory tests include platelet function test (PFT) and genetic detection andare available to fulfill PAPT in a relatively objective manner. Nevertheless, the routine measurement of platelet reactivity has not been widely implemented, and lack of consensus concerning optimal method and the best cut-off value associated with clinical risk has hindered the consideration of platelet function testing in clinical guidelines. According to a systematic review performed by Winter et al. [8], although PAPT monitored by PFT seems to be feasible, the contradictory results of smaller registry studies and larger randomized trials with regards to outcome remains uncertain. Another approach is the genotype test. As a pro-drug, clopidogrel requires enteric and hepatic transformation by the cytochrome P450 (CYP) system to exert its antiplatelet effect. CYP2C19 enzyme seems to have the most prominent role in the production of clopidogrel active metabolite, while CYP2B6, CYP1A2, CYP3A/A5, and CYP2C9 show lesser involvement [9]. According to the systematic review performed by Osnabrugge et al. [10], at least 11 meta-analyses on the association between CYP2C19 loss-of-function alleles and clinical efficacy of clopidogrel were identified until 2014. However, the conclusions of these meta-analyses were not consistent.

Recently, many studies evaluating the risk of MACEs and bleeding events were performed among patients receiving clopidogrel carrying dif- ferent CYP2C19 genotypes or presenting different HTPR status as measured by PFT, including several randomized controlled trials (RCTs), such as GRAVITAS [11]. However, the conclusions of these studies are not consistent. In this study, a metaanalysis was performed to further evaluate the benefits of PAPT in coronary artery disease (CAD) patients. Compared with previous studies, our meta-analysis included all PAPT available, not only PFTs but also genetic detection as intervention.

\section{Methods}

\section{Trial selection and search strategy}

All published RCTs enrolling CAD patients treated with PAPT according to genetic detection or PFT for at least 1 month were selected. Controlled intervention was the standard antiplatelet therapy not guided by genetic detection or PFT.

The search involved various computerized databases: PubMed (up to 31 May 2017), Embase (up to 31 May 2017), and Cochrane Controlled Trials Register (up to May 2017), searching the following items: genotype OR (genetic testing) OR (genetic polymorphism) OR (platelet function testing) OR (platelet reactivity) OR (VerifyNow) OR plateletworks OR (light transmission aggregometry) OR (multiple electrode aggregometry) OR (Platelet Function Analyzer) OR (vasodilator stimulated phosphoprotein) OR (thrombelastography) OR (Cone and Platelet Analyzer)) AND (clopidogrel) OR (cangrelor) OR (elinogrel) OR (prasugrel) OR (ticagrelor), with the following filters: "Clinical Trial, Humans, English" in PubMed and "Controlled Clinical Trial, Humans, English" in Embase. In addition, the references of the collected studies were checked for additional analysis.

Trials belonging to the following categories were excluded: (i) non-RCTs; (ii) subjects not treated with P2Y12 receptor antagonist; (iii) treatment duration < 1 month; and (iv) trials with no mention of MACEs or bleeding events prevention. Two investigators (Y. Zhang and P. Zhang) independently selected the studies according to the following steps: (i) titles and abstracts examination to remove irrelevant reports; (ii) full text collection of potentially relevant reports; (iii) full-text reports examination for compliance of studies with eligibility criteria; and (iv) final decisions on study inclusion and data collection. Any discrepancies were resolved by consensus. If a consensus could not be reached, the senior author (Y.L. Hou) made the final decision for trial eligibility and data extraction. 


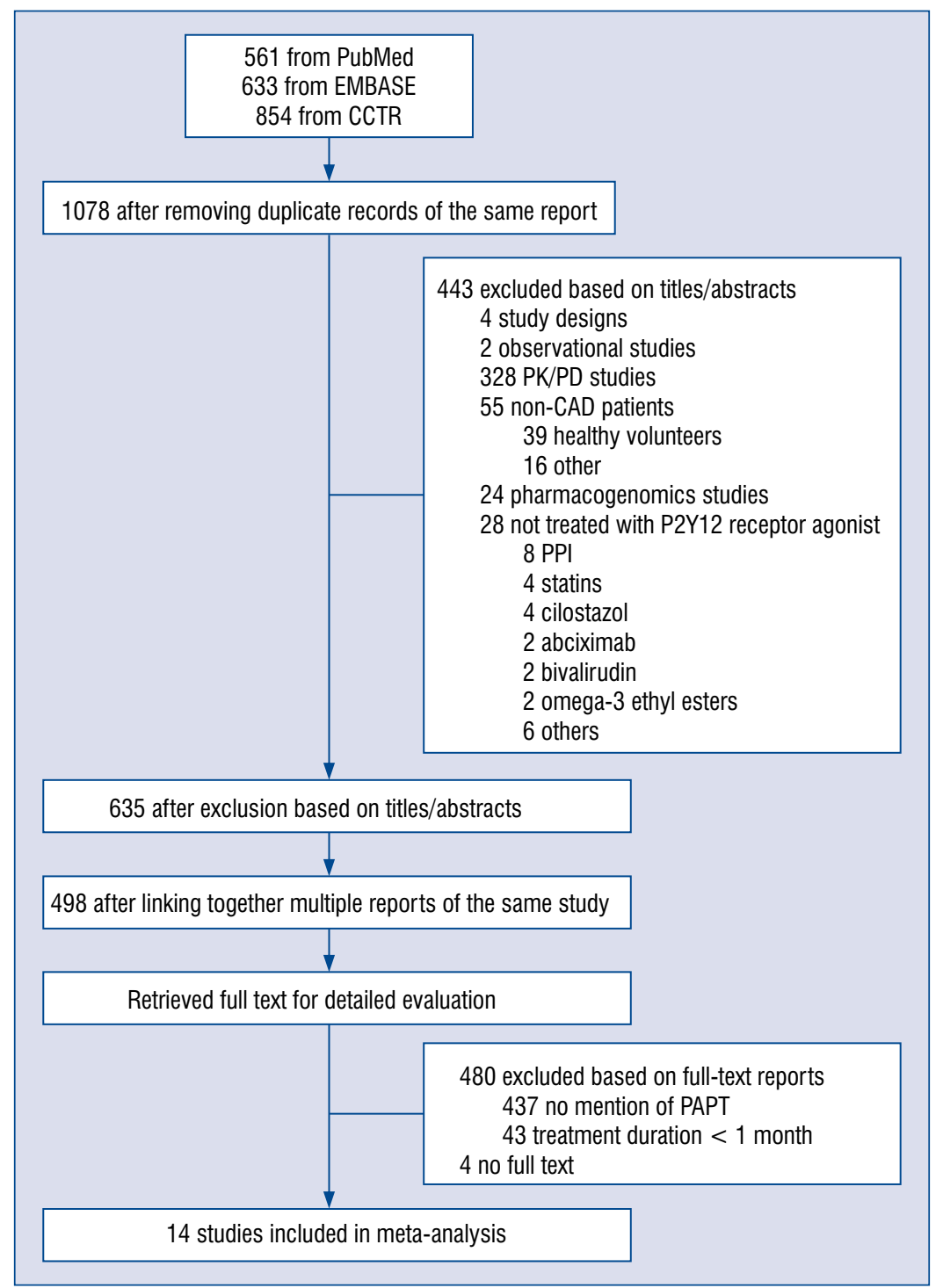

Figure 1. Flow diagram of the trial selection process; CAD - coronary artery disease; CCTR - Cochrane Controlled Trials Register; PK — pharmacokinetics; PD — pharmacodynamics; PPI — proton-pump inhibitor; PAPT — personalized antiplatelet therapy.

\section{Statistical analysis}

Results of the outcome were expressed as risk ratio (RR) with $95 \%$ confidence interval (CI) for each study. A pooled effect was calculated using a random-effects model. Heterogeneity was assessed using Q and $\mathrm{I}^{2}$ statistic. Subgroup analysis and meta-regression were performed to localize the source of heterogeneity. Sensitivity analysis was performed through the trim and fill method. Publication bias was evaluated using funnel plot and Egger's regression method. All statistical analyses were performed using Review Manager 5.3 and STATA 12.0. Statistical significance was defined as $\mathrm{p}<0.05$ ( 2 -sided).

\section{Results}

A total number of 1055 relevant articles were retrieved from PubMed (561), Embase (633), and Cochrane Controlled Trials Register (854). Among them, 14 studies [11-24] reporting the differences in terms of MACEs and bleeding events between 9497 patients with and without the PAPT were considered eligible for our meta-analysis (4878 randomized to PAPT and 4619 to control) (Fig. 1). The baseline characteristics of the patients and trials key features are shown in Table 1 . All the enrolled patients suffered from CAD and underwent stenting. The antiplatelet strategy in PAPT 


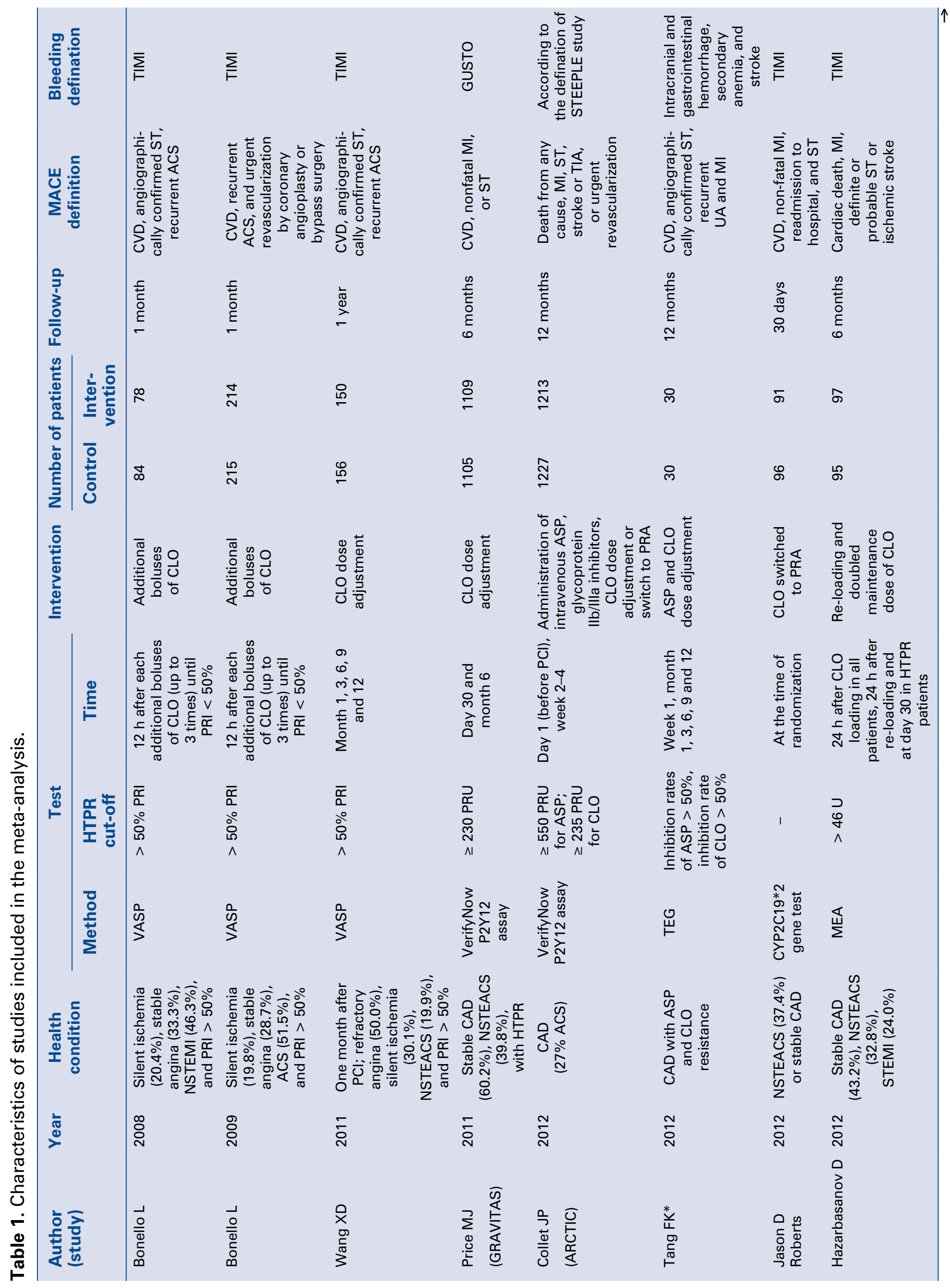




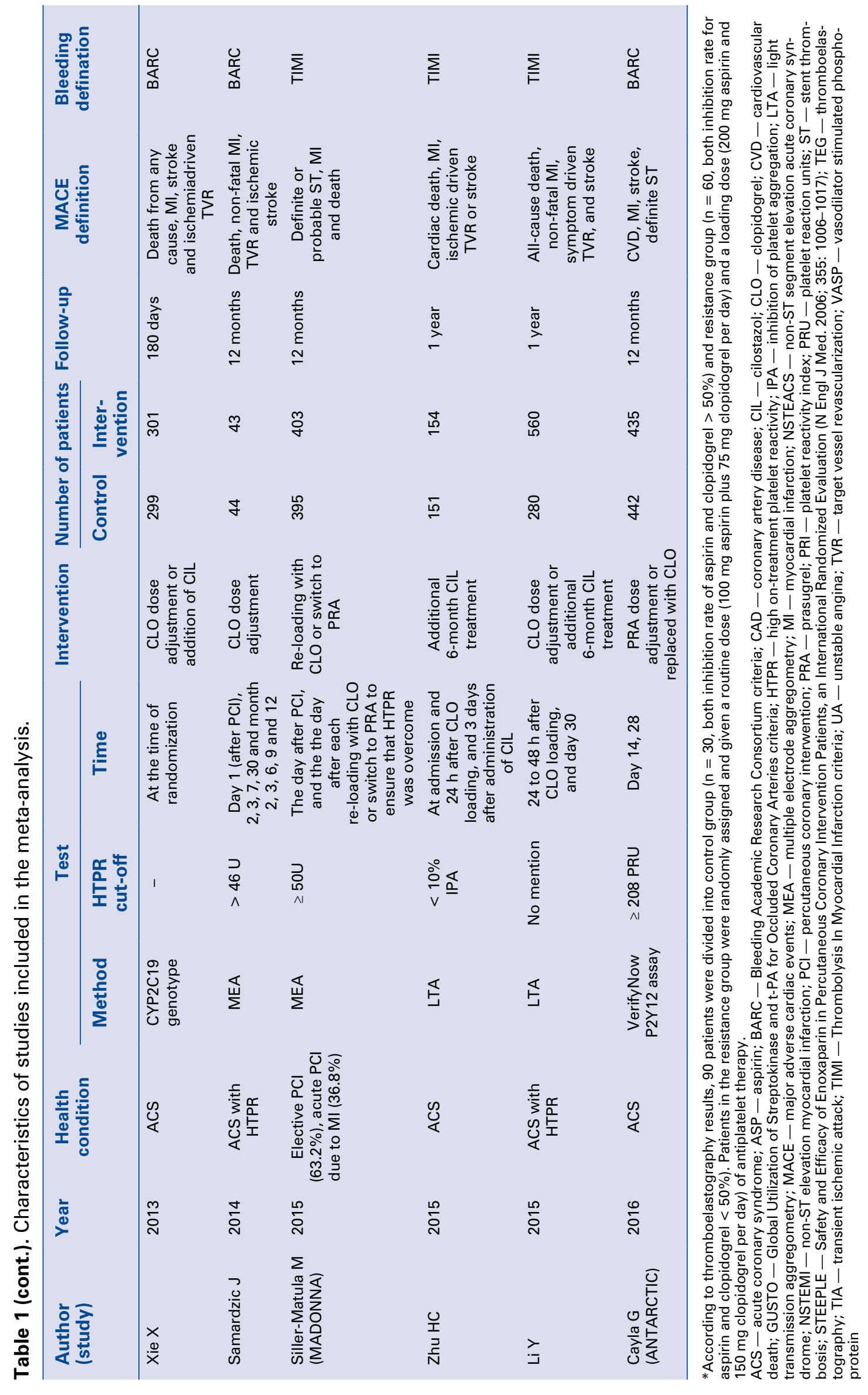


groups was adjusted according to genotype or PFT. In addition, there were 4 abstracts from European Society of Cardiology Congress 2016 involving the benefits of PAPT in CAD patients, but they were not included because of the lack of full text (P1835, P4214, P5598, and P5601).

The studies showed a significantly increased risk of MACEs (RR $0.58,95 \%$ CI $0.42-0.80, \mathrm{p}=$ $=0.001$ ), stent thrombosis (ST; RR 0.60, 95\% CI 0.41-0.87, $\mathrm{p}=0.008$ ) and myocardial infarction (MI; RR 0.43, 95\% CI 0.21-0.88, $\mathrm{p}=0.02$ ) in patients receiving PAPT compared to the standard therapy group. Furthermore, no statistically significant difference was observed between the above two groups in cardiovascular (CV) death (RR 0.77, 95\% CI 0.51-1.16, $\mathrm{p}=0.21$ ), bleeding events (RR 0.96, 95\% CI 0.81-1.13, p = 0.59) and ischemic stroke (RR 0.81; 95\% CI 0.39-1.66, $\mathrm{p}=$ $=0.57)$. However, the heterogeneity was substantial in MACEs $\left(\mathrm{Chi}^{2}=58.71, \mathrm{p}<0.00001, \mathrm{I}^{2}=81 \%\right)$ and $\mathrm{MI}\left(\mathrm{Chi}^{2}=35.57, \mathrm{p}<0.0001, \mathrm{I}^{2}=78 \%\right)$ groups (Fig. 2).

In order to identify the heterogeneity source in MACEs group, meta-regression and subgroup analyses were performed. The results revealed that the benefits of receiving PAPT had no clear linear relation with the follow-up period (Coef. $=0.120$, Std. Err. $=0.059, \mathrm{p}=0.068$ ) (Fig. 3). However according to subgroup analysis, there was obvious difference among the benefits after 1,6 and 12 months (among subgroups: $\mathrm{Chi}^{2}=8.90$, $\left.\mathrm{p}=0.01, \mathrm{I}^{2}=77.5 \%\right)$, but the heterogeneity was not well located ( 1 month: $\mathrm{Chi}^{2}=0.01, \mathrm{p}=0.92$, $\mathrm{I}^{2}=0 \% ; 6$ months: $\mathrm{Chi}^{2}=8.33, \mathrm{p}=0.02, \mathrm{I}^{2}=76 \%$; 12 months: $\left.\mathrm{Chi}^{2}=33.57, \mathrm{p}<0.00001, \mathrm{I}^{2}=82 \%\right)$. Another subgroup analysis revealed that the benefits of PAPT was more significant in the HTPR subgroup (RR 0.46; 95\% CI 0.27-0.80, p = 0.006), but not in the no mention subgroup (RR $0.70 ; 95 \%$ CI $0.48-1.00, \mathrm{p}=0.05)$. However, the heterogeneity was substantial in each subgroup (HTPR: $\mathrm{Chi}^{2}=13.29, \mathrm{p}=0.02, \mathrm{I}^{2}=62 \%$; No mention: $\mathrm{Chi}^{2}=29.29, \mathrm{p}<0.0001, \mathrm{I}^{2}=83 \%$; between subgroups: $\left.\mathrm{Chi}^{2}=1.48, \mathrm{p}=0.22, \mathrm{I}^{2}=32.3 \%\right)$. Finally, based on PAPT strategy difference, the source of heterogeneity was located. Although the numbers of trials in each subgroup were small, the heterogeneities in each subgroup were not obvious (light transmission aggregometry [LTA]: $\mathrm{Chi}^{2}=0.63, \mathrm{p}=0.43, \mathrm{I}^{2}=0 \%$; multiple electrode aggregometry [MEA]: $\mathrm{Chi}^{2}=1.36, \mathrm{p}=0.51, \mathrm{I}^{2}=0 \%$; VerifyNow: $\mathrm{Chi}^{2}=0.96, \mathrm{p}=0.62, \mathrm{I}^{2}=0 \%$; vasodilator stimulated phosphoprotein [VASP]: $\mathrm{Chi}^{2}=7.04$, $\mathrm{p}=0.03, \mathrm{I}^{2}=72 \%$ ), and it was found that all methods could obtain obvious benefits except VerifyNow and VASP (LTA: RR 0.55, 95\% CI 0.37-0.83, p = 0.004; MEA: RR 0.47, 95\% CI 0.32-0.67, p < 0.0001; CYP2C19 gene test: RR $0.29,95 \%$ CI $0.14-0.64$, $\mathrm{p}=0.002$; VerifyNow: RR $1.08,95 \%$ CI $0.98-1.19$, $\mathrm{p}=0.12$; VASP: RR 0.15, 95\% CI 0.02-1.00, $\mathrm{p}=0.05$ ) (Fig. 4).

Sensitivity analysis was performed through the Trim and Fill method, and no obvious difference was found after Trim and Fill processes, suggesting that the pooled estimates in each group were relatively robust (Table 2 ). Another post-hoc sensitivity analysis was performed by omitting studies on the basis of subgroup analysis. It seems that VerifyNow assay is outlier, so all outcomes were redone without studies using VerifyNow, wherein similar results were obtained (Table 3 ). According to the funnel plot (Fig. 5) and Egger's regression (Table 2), obvious publication biases were found in MACEs (Intercept: $-2.726,95 \% \mathrm{CI}-3.657$ to $-1.796, \mathrm{p}=0.000$ ), CV death (Intercept: -1.741 , $95 \% \mathrm{CI}-2.472$ to $-1.010, \mathrm{p}=0.000)$, MI (Intercept: $-1.649,95 \% \mathrm{CI}-3.090$ to $-0.207, \mathrm{p}=0.030$ ), and ST (Intercept: $-1.582,95 \%$ CI -2.801 to -0.362 , $\mathrm{p}=0.016$ ) groups.

\section{Discussion}

In recent years, the precision of medicine has been increasingly attracting attentions, PFTs and pharmacogenomics have been rapidly developing and are becoming an important approach for PAPT in reducing the risk of MACEs occurrence after stenting, especially in patients with HTPR, exactly as the present meta-analysis has discovered. According to a recent RCT, both genotyping (CYP2C19) and PFT (VerifyNew p2Y12 assay) all resulted in an improved platelet inhibition [25].

\section{Platelet function testing}

At present, many PFT methods are available, while the cut-off values of clopidogrel low response are different due to different test methods. A study [26] published in JAMA in 2010 compared the relationship between different PFT methods and clinical outcomes in 1069 patients undergoing elective PCI and taking clopidogrel from 2005 to 2007. LTA, VerifyNow P2Y12, Plateletworks assays, IMPACT-R and platelet function analyzer (PFA-100) were used to test the platelet activity during treatment, with the application of receiver operating characteristic curve to analyze whether the cut-off has diagnostic value, as well as an outcome event such as death, non-fatal MI, ST, and 


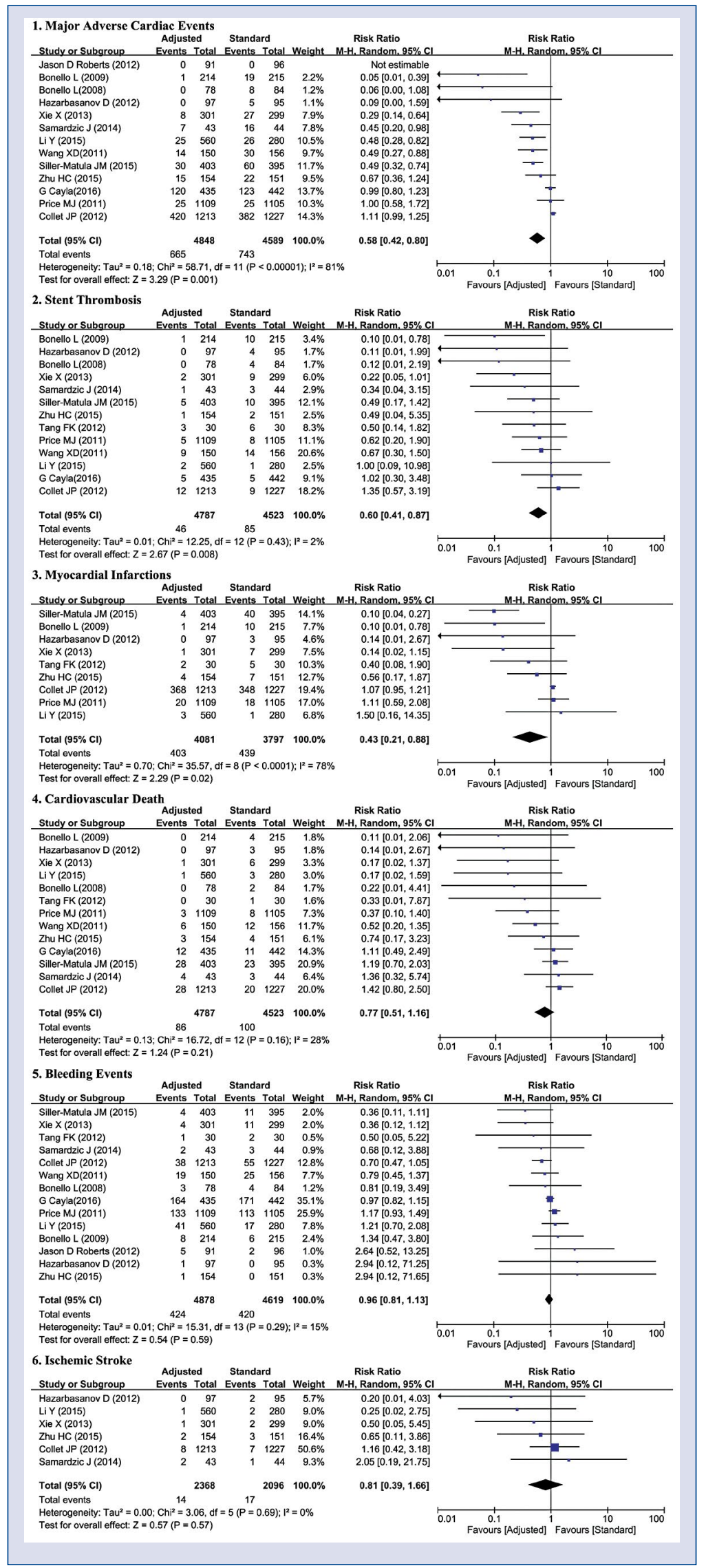

Figure 2. Forest plot comparing the effects of laboratory versus experiential personalized antiplatelet therapy; $\mathrm{Cl}$ confidence interval. 


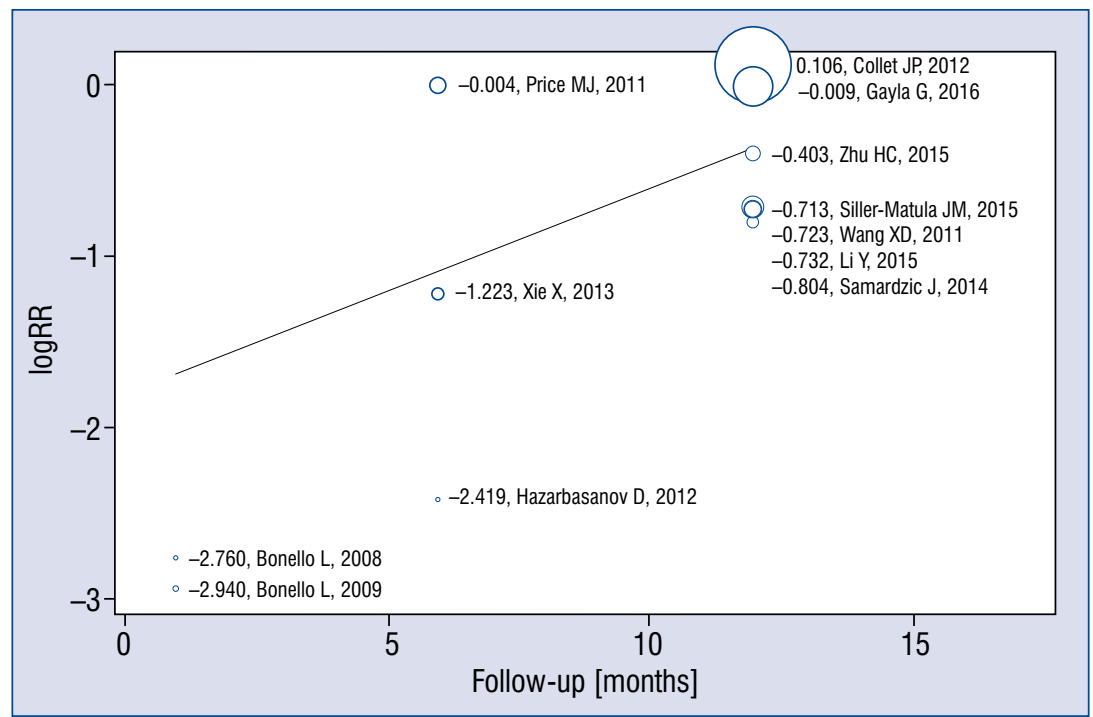

Figure 3. Meta-regression to estimate the relationship between the benefits of personalized antiplatelet therapy and follow-up period; Coef. $=0.120$, Std. Err. $=0.059, \mathrm{p}=0.068$.

ischemic stroke. After 1 year, the results showed that only LTA, VerifyNow, and Plateletworks were significantly associated with the primary end point. However, the predictive accuracy of these tests were only modest. None of the tests provided accurate prognostic information to identify low-risk patients at higher risk of bleeding following stent implantation.

The results of our meta-analysis revealed that the preventive effects of PAPT on MACEs were more evident during a short follow-up period, and the difference was statistically significant according to the subgroup analysis, specially between 1 month and 12 month subgroups (1 month: RR 0.06, 95\% CI 0.01-0.29, $\mathrm{p}=0.0006$; 6 months: RR $0.44,95 \%$ CI $0.14-1.42, \mathrm{p}=0.17 ; 12$ months: RR $0.68,95 \%$ CI $0.50-0.93, \mathrm{p}=0.01$; heterogeneity among subgroups: $\mathrm{Chi}^{2}=8.90, \mathrm{p}=0.01$ ). During antiplatelet therapy in patients after coronary stenting, the platelet function is constantly changing, suggesting that the PFT time window is potentially influencing PAPT benefits. During a short follow-up research, the proportion of this time window in follow-up period is higher, thus the benefits might be greater. However, this speculation needs more short follow-up periods or a wider PFT time window to verify.

The subgroup analysis based on PAPT strategy found that all methods could provide benefits except VerifyNow, although no statistical difference was found among all strategic results. Due to its mature detection method, VerifyNow results have high specificity and sensibility, thus the stated hy- pothesis was that the above non-significant results were related with the VerifyNow cut-off value. It is generally accepted that $\geq 230 \mathrm{U}$ can be considered as HTPR in the VerifyNow method, but the cut-off value remains controversial. Perhaps a lower cutoff of $208 \mathrm{U}$ is more suitable, as suggested in one meta-analysis [27] and ANTARCTIC study [24].

\section{Genetic detection}

Currently, several pharmacogenetic studies have found that gene loci plurality was related to cardiovascular events, which might predict the reactivity of antiplatelet medicine [28, 29]. Polymorphisms are present in many genes including P2Y12, GP IIb/IIIa, GP Ia/IIa, GP Ib/IX/V, CYP2C19, CYP2C9, CYP3A4, CYP3A5, COX-1, COX-2 and ABCB1 [29, 30]. However, at present CYP2C19 gene polymorphism is the only one related to clopidogrel antiplatelet effect [31,32]. The loss-of-function gene (CYP2C19*2,*3) carriers show low reaction to clopidogrel [33], while carriers of gain-of-function gene (CYP2C19*17) tend to show higher hemorrhage risk [34].

Clopidogrel and prasugrel are all thienopyridine prodrugs, and all need CYP450 enzyme metabolism to translate into the activated product. Clopidogrel is predominantly converted to an inactive derivative, with only a minor fraction (15\%) undergoing the 2 -sequential oxidation steps to generate the active metabolite [35]. CYP2C19, CYP3A4/5 and CYP1A2 are all important enzymes in this process. The metabolic efficiency of prasugrel is relatively higher, with more than $50 \%$ of 


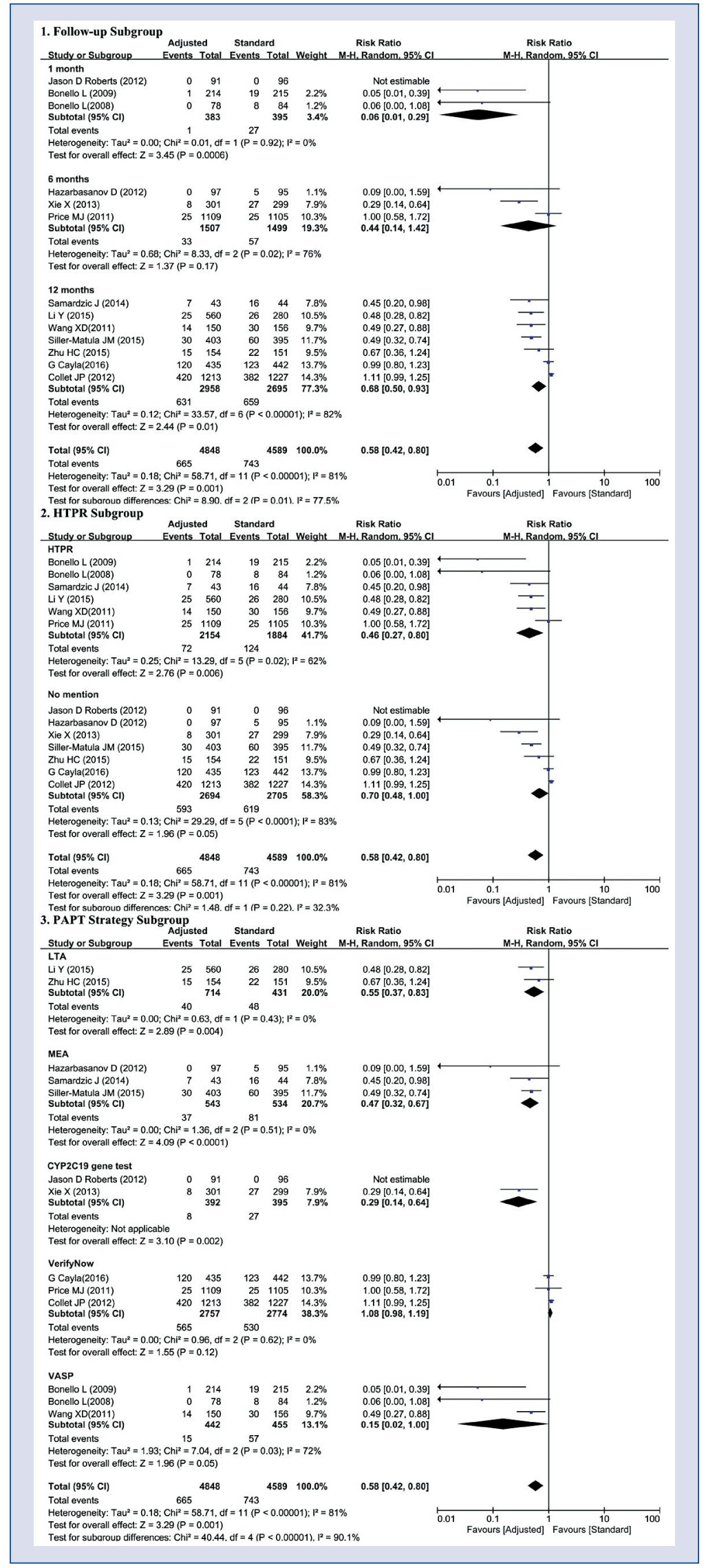

Figure 4. Subgroup analysis based on personalized antiplatelet therapy (PAPT) strategy difference; HTPR - high on-treatment platelet reactivity; LTA — light transmission aggregometry; MEA — multiple electrode aggregometry; VASP - vasodilator stimulated phosphoprotein; $\mathrm{Cl}$ - confidence interval. 
Table 2. Publication bias and sensitivity analysis.

\begin{tabular}{|c|c|c|c|c|c|c|}
\hline \multirow[t]{3}{*}{ Group } & \multicolumn{2}{|l|}{ Egger's regression } & \multicolumn{4}{|c|}{ Trim and Fill method } \\
\hline & \multirow[t]{2}{*}{ Intercept (95\% CI) } & \multirow[t]{2}{*}{$\mathbf{P}$} & \multirow{2}{*}{$\begin{array}{l}\text { Iter- } \\
\text { ation }\end{array}$} & \multirow{2}{*}{$\begin{array}{c}\text { No. } \\
\text { of } \\
\text { Trim }\end{array}$} & \multicolumn{2}{|c|}{$\operatorname{RR}(95 \% \mathrm{Cl})$} \\
\hline & & & & & Before Trim and Fill & After Trim and Fill \\
\hline MACE & $-2.726(-3.657$ to -1.796$)$ & 0.000 & 2 & 0 & $0.58(0.42-0.80)$ & $0.58(0.42-0.80)$ \\
\hline Cardiovascular death & $-1.741(-2.472$ to -1.010$)$ & 0.000 & 2 & 0 & $0.77(0.51-1.16)$ & $0.77(0.51-1.16)$ \\
\hline Myocardial infarction & $-1.649(-3.090$ to -0.207$)$ & 0.030 & 2 & 0 & $0.43(0.21-0.88)$ & $0.43(0.21-0.88)$ \\
\hline Stroke & $-1.188(-3.153$ to 0.777$)$ & 0.169 & 2 & 0 & $0.81(0.39-1.66)$ & $0.81(0.39-1.66)$ \\
\hline Stent thrombosis & $-1.582(-2.801$ to -0.362$)$ & 0.016 & 2 & 0 & $0.60(0.41-0.87)$ & $0.60(0.41-0.87)$ \\
\hline Bleeding & $-0.246(-1.155$ to 0.663$)$ & 0.566 & 2 & 1 & $0.96(0.81-1.13)$ & $0.96(0.82-1.12)$ \\
\hline
\end{tabular}

$\mathrm{Cl}$ - confidence interval; MACE - major adverse cardiac events; RR - risk ratio

Table 3. Sensitivity analysis after omitting studies using VerifyNow.

\begin{tabular}{|c|c|c|c|c|c|c|}
\hline & \multicolumn{3}{|c|}{ Before omitting } & \multicolumn{3}{|c|}{ After omitting } \\
\hline & $\begin{array}{l}\text { Number of } \\
\text { studies }\end{array}$ & RR (95\% Cl) & $\mathbf{p}$ & $\begin{array}{l}\text { Number of } \\
\text { studies }\end{array}$ & RR (95\% Cl) & $\mathbf{p}$ \\
\hline MACE & 13 & $0.58(0.42-0.80)$ & 0.001 & 10 & $0.44(0.32-0.59)$ & $<0.00001$ \\
\hline Cardiovascular death & 13 & $0.77(0.51-1.16)$ & 0.21 & 10 & $0.60(0.34-1.06)$ & 0.08 \\
\hline Myocardial infarction & 9 & $0.43(0.21-0.88)$ & 0.02 & 7 & $0.25(0.11-0.54)$ & 0.0005 \\
\hline Stroke & 6 & $0.81(0.39-1.66)$ & 0.57 & 5 & $0.56(0.20-1.57)$ & 0.27 \\
\hline Stent thrombosis & 13 & $0.60(0.41-0.87)$ & 0.008 & 10 & $0.44(0.27-0.70)$ & 0.0006 \\
\hline Bleeding & 14 & $0.96(0.81-1.13)$ & 0.59 & 11 & $0.89(0.65-1.21)$ & 0.46 \\
\hline
\end{tabular}

$\mathrm{Cl}$ - confidence interval; MACE — major adverse cardiac events; RR — risk ratio

the drug becoming bioactivated, and primarily mediated by CYP3A4 and CYP2B6 enzymes [36].

Currently, the effect of CYP2C19 polymorphisms on clopidogrel therapy has been extensively studied. The earliest report on the correlation between CYP2C19*2 loss-of-function gene and clopidogrel low reaction dates back to 2006 [37]. More studies performed at later dates confirmed this correlation [38-40]. CYP2C19*17 gain-of-function gene is related to a reactivity increase of clopidogrel, but recent studies found that this correlation may be due to CYP2C19*2 linkage disequilibrium [41]. However, prasugrel is not significantly influenced by gene polymorphism, although some studies suggest an association [42, 43]. Subgroup analysis of TRITON-TIMI $38 \mathrm{did}$ not find significant associations between common CYP variants and active metabolite levels, platelet inhibition, or clinical CV event rates [44].

Clopidogrel and prasugrel are both substrates of p-glucoprotein efflux pump, which is encoded by the ABCB1 gene. Nevertheless, the correlation between $\mathrm{ABCB} 1$ polymorphism and clopidogrel pharmacodynamics is still unclear. One research paper found that patients with ABCB1 C3435T genotype had decreased clopidogrel absorption and circulating metabolite plasma levels [45], and in TRITON-TIMI 38 study, this gene polymorphism was significantly associated with an increased risk of $\mathrm{CV}$ death, MI, or stroke in patients under clopidogrel treatment [44]. However, the GIFT study revealed that $\mathrm{ABCB} 1$ polymorphism was not a significant factor in pharmacologic or clinical outcomes in patients treated with clopidogrel [46].

Multiple studies have investigated the influence of other gene polymorphisms, such as CYP2C9, CYP3A4, CYP3A5, P2Y12 on clopidogrel response variability, with results being mostly non-significant [36]. The GIFT study observed the correlation between 17 gene loci and platelet reactivity in more than 1,000 patients receiving standard or high-dose clopidogrel after PCI, and found that only CYP2C19*2 was associated with HTPR [46]. 

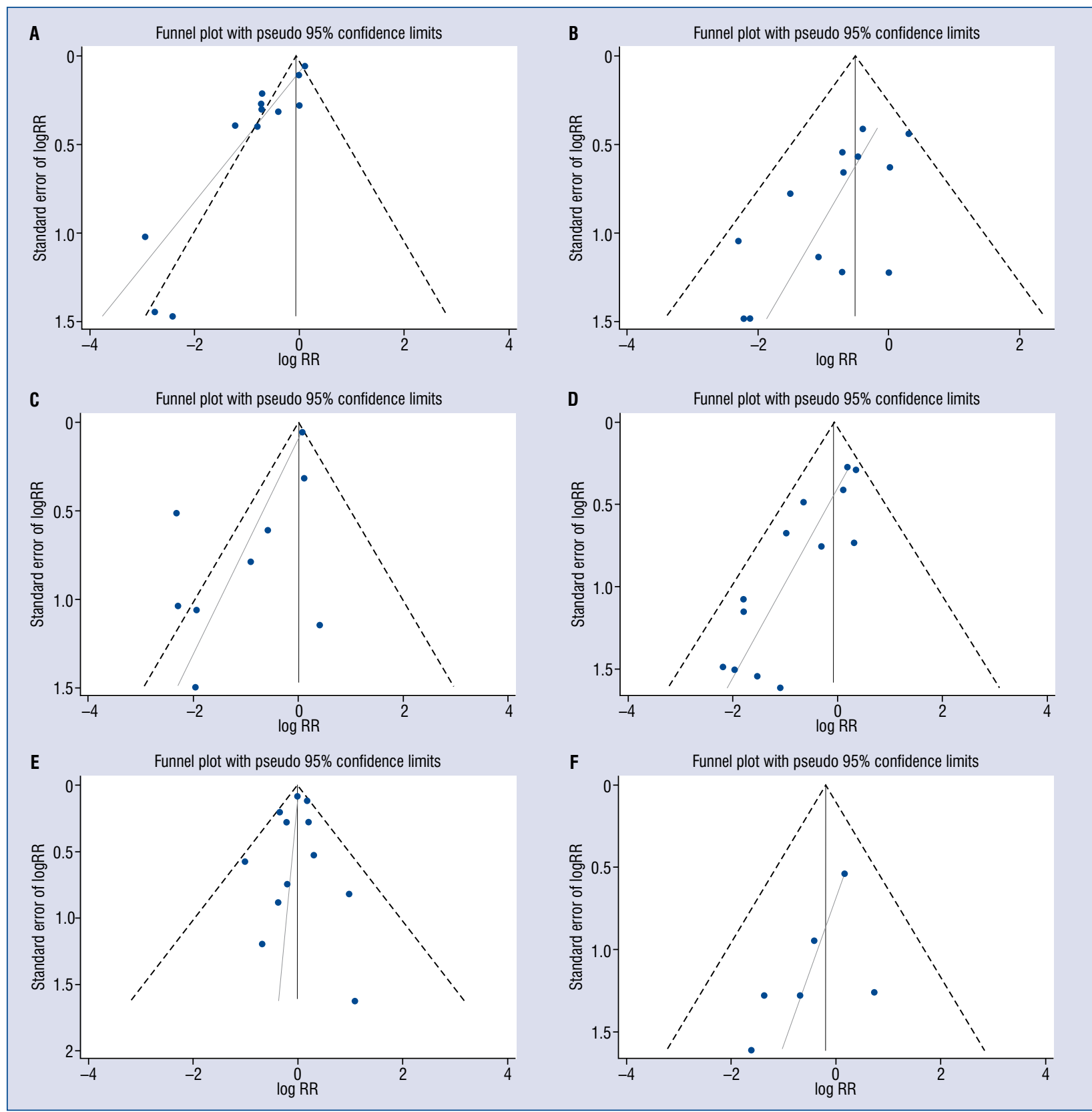

Figure 5. Funnel plot; A. Major adverse cardiac events subgroup; B. Stent thrombosis subgroup; C. Myocardial infarctions subgroup; D. Cardiovascular death subgroup; E. Bleeding events subgroup; F. Stroke subgroup.

Ticagrelor is a new non-thienopyridine antiplatelet medicine, which in 2011 was approved for use in patients with ACS or a history of MI. Studies on ticagrelor pharmacogenetics are limited, and no significant association between its effects and certain genotypes have been found. The subgroup analysis of DISPERSE and DISPERSE-2 studies investigated the correlation between P2Y12, P2Y1, ITGB3 gene polymorphism and the effects of ticagrelor, and found no association [47]. Besides, RESPOND and ONSET/OFFSET studies found that the effect of ticagrelor is unrelated to CYP2C19 and ABCB1 gene polymorphism [48]. The data of the PLATO trial were further investigated to search for potential genetic determinants, with at least 2 genome wide association study (GWAS) failing to find any significant effect of therapy associated polymorphisms on clinical outcomes $[49,50]$. 


\section{Publication bias}

The funnel plots are obviously asymmetric, which indicate a potential publication bias in this meta-analysis. And Egger's regression was performed because the interpretation of funnel plots is largely subjective. Although the absence of a significant correlation or regression cannot be taken as evidence of symmetry, it confirmed publication bias from another perspective (Table 2). After that, a more interesting question would be what is its impact on these conclusions? It was identified from the results of trim and fill processes, which was performed in the sensitivity analysis. After the trim and fill adjustment, 3 imputed studies are shown as filled circles, and imputed point estimate in log units is shown as a filled diamond at $0.156(0.085,0.227)$, corresponding to a OR of $1.169(1.089,1.254)$. The adjusted point estimate suggests a lower benefit than the original analysis. Thus, the adjusted estimate is fairly close to the original, and it was thought that they have similar substantive implications.

\section{Conclusions}

In conclusion, patients undergoing coronary stenting, PAPT could reduce the risk of MACEs, ST and MI. The preventive effect on MACEs was more significant in patients with HTPR. However, there was no significant increase in $\mathrm{CV}$ death, bleeding events and ischemic stroke.

\section{Acknowledgements}

Thanks go to all the staff at Jinan Quanfang Science and Technology Co., Ltd. for their bibliographic retrieval service.

\section{Conflict of interest: None declared}

\section{References}

1. Levine GN, Bates ER, Bittl JA, et al. 2016 ACC/AHA Guideline Focused Update on Duration of Dual Antiplatelet Therapy in Patients With Coronary Artery Disease: A Report of the American College of Cardiology/American Heart Association Task Force on Clinical Practice Guidelines: An Update of the 2011 ACCF/AHA/ /SCAI Guideline for Percutaneous Coronary Intervention, 2011 ACCF/AHA Guideline for Coronary Artery Bypass Graft Surgery, 2012 ACC/AHA/ACP/AATS/PCNA/SCAI/STS Guideline for the Diagnosis and Management of Patients With Stable Ischemic Heart Disease, 2013 ACCF/AHA Guideline for the Management of STElevation Myocardial Infarction, 2014 AHA/ACC Guideline for the Management of Patients With Non-ST-Elevation Acute Coronary Syndromes, and 2014 ACC/AHA Guideline on Perioperative Cardiovascular Evaluation and Management of Patients Undergoing Noncardiac Surgery. Circulation. 2016; 134(10): e123-e155.
2. Kolh P, Windecker S, Alfonso F, et al. 2014 ESC/EACTS Guidelines on myocardial revascularization: the Task Force on Myocardial Revascularization of the European Society of Cardiology (ESC) and the European Association for Cardio-Thoracic Surgery (EACTS). Developed with the special contribution of the European Association of Percutaneous Cardiovascular Interventions (EAPCI). Eur J Cardiothorac Surg. 2014; 46(4): 517-592, doi: 10.1093/ejcts/ezu366, indexed in Pubmed: 25173601.

3. Gurbel PA, Bliden KP, Hiatt BL, et al. Clopidogrel for coronary stenting: response variability, drug resistance, and the effect of pretreatment platelet reactivity. Circulation. 2003; 107(23): 2908-2913, doi: 10.1161/01.CIR.0000072771.11429.83, indexed in Pubmed: 12796140.

4. Matetzky S, Shenkman B, Guetta V, et al. Clopidogrel resistance is associated with increased risk of recurrent atherothrombotic events in patients with acute myocardial infarction. Circulation. 2004; 109(25): 3171-3175, doi: 10.1161/01. CIR.0000130846.46168.03, indexed in Pubmed: 15184279.

5. Tantry US, Bonello L, Aradi D, et al. Working Group on OnTreatment Platelet Reactivity. Consensus and update on the definition of on-treatment platelet reactivity to adenosine diphosphate associated with ischemia and bleeding. J Am Coll Cardiol. 2013; 62(24): 2261-2273, doi: 10.1016/j.jacc.2013.07.101, indexed in Pubmed: 24076493.

6. Siller-Matula JM, Trenk D, Schrör K, et al. EPA (European Platelet Academy). Response variability to P2Y12 receptor inhibitors: expectations and reality. JACC Cardiovasc Interv. 2013; 6(11): 1111-1128, doi: 10.1016/j.jcin.2013.06.011, indexed in Pubmed: 24262612.

7. Sofi F, Giusti B, Marcucci R, et al. Cytochrome P450 2C19*2 polymorphism and cardiovascular recurrences in patients taking clopidogrel: a meta-analysis. Pharmacogenomics J. 2011; 11(3): 199-206, doi: 10.1038/tpj.2010.21, indexed in Pubmed: 20351750.

8. Winter MP, Koziński M, Kubica J, et al. Personalized antiplatelet therapy with P2Y12 receptor inhibitors: benefits and pitfalls. Post Kardiol Interw. 2015; 11(4): 259-280, doi: 10.5114/ pwki.2015.55596, indexed in Pubmed: 26677375.

9. Huber K. Genetic variability in response to clopidogrel therapy: clinical implications. Eur Heart J. 2010; 31(24): 2974-2976, doi: 10.1093/eurheartj/ehq329, indexed in Pubmed: 20846994.

10. Osnabrugge RL, Head SJ, Zijlstra F, et al. A systematic review and critical assessment of 11 discordant meta-analyses on reduced-function CYP2C19 genotype and risk of adverse clinical outcomes in clopidogrel users. Genet Med. 2015; 17(1): 3-11, doi: 10.1038/gim.2014.76, indexed in Pubmed: 24946154.

11. Price MJ, Berger PB, Teirstein PS, et al. Standard- vs high-dose clopidogrel based on platelet function testing after percutaneous coronary intervention: the GRAVITAS randomized trial. JAMA. 2011; 305(11): 1097-1105, doi: 10.1001/jama.2011.290, indexed in Pubmed: 21406646.

12. Collet JP, Cuisset T, Rangé G, et al. ARCTIC Investigators. Bedside monitoring to adjust antiplatelet therapy for coronary stenting. N Engl J Med. 2012; 367(22): 2100-2109, doi: 10.1056/ NEJMoa1209979, indexed in Pubmed: 23121439.

13. Samardzic J, Krpan M, Skoric B, et al. Serial clopidogrel dose adjustment after platelet function testing improves outcome of acute coronary syndrome patients undergoing percutaneous coronary intervention with high on-treatment platelet reactivity. J Thromb Thrombolysis. 2014; 38(4): 459-469, doi: 10.1007/ s11239-014-1087-0, indexed in Pubmed: 24853829.

14. Xie X, Ma YT, Yang YN, et al. Personalized antiplatelet therapy according to CYP2C19 genotype after percutaneous coronary 
intervention: a randomized control trial. Int J Cardiol. 2013; 168(4): 3736-3740, doi: 10.1016/j.ijcard.2013.06.014, indexed in Pubmed: 23850318.

15. Siller-Matula JM, Gruber C, Francesconi M, et al. The net clinical benefit of personalized antiplatelet therapy in patients undergoing percutaneous coronary intervention. Clin Sci (Lond). 2015; 128(2): 121-130, doi: 10.1042/CS20140310, indexed in Pubmed: 25124236.

16. Tang Fk, Lin Lj, Hua N, et al. Earlier application of loading doses of aspirin and clopidogrel decreases rate of recurrent cardiovascular ischemic events for patients undergoing percutaneous coronary intervention. Chin Med J (Engl). 2012; 125(4): 631-638, indexed in Pubmed: 22490487.

17. Roberts JD, Wells GA, Le May MR, et al. Point-of-care genetic testing for personalisation of antiplatelet treatment (RAPID GENE): a prospective, randomised, proof-of-concept trial. Lancet. 2012; 379(9827): 1705-1711, doi: 10.1016/S01406736(12)60161-5, indexed in Pubmed: 22464343.

18. Hazarbasanov D, Velchev V, Finkov B, et al. Tailoring clopidogrel dose according to multiple electrode aggregometry decreases the rate of ischemic complications after percutaneous coronary intervention. J Thromb Thrombolysis. 2012; 34(1): 85-90, doi: 10.1007/s11239-012-0684-z, indexed in Pubmed: 22249353.

19. Wang XD, Zhang DF, Zhuang SW, et al. Modifying clopidogrel maintenance doses according to vasodilator-stimulated phosphoprotein phosphorylation index improves clinical outcome in patients with clopidogrel resistance. Clin Cardiol. 2011; 34(5): 332-338, doi: 10.1002/clc.20884, indexed in Pubmed: 21538380.

20. Bonello L, Camoin-Jau L, Armero S, et al. Tailored clopidogrel loading dose according to platelet reactivity monitoring to prevent acute and subacute stent thrombosis. Am J Cardiol. 2009; 103(1): 5-10, doi: 10.1016/j.amjcard.2008.08.048, indexed in Pubmed: 19101221.

21. Bonello L, Camoin-Jau L, Arques S, et al. Adjusted clopidogrel loading doses according to vasodilator-stimulated phosphoprotein phosphorylation index decrease rate of major adverse cardiovascular events in patients with clopidogrel resistance: a multicenter randomized prospective study. J Am Coll Cardiol. 2008; 51(14): 1404-1411, doi: 10.1016/j.jacc.2007.12.044, indexed in Pubmed: 18387444.

22. Zhu HC, Li Yi, Guan SY, et al. Efficacy and safety of individually tailored antiplatelet therapy in patients with acute coronary syndrome after coronary stenting: a single center, randomized, feasibility study. J Geriatr Cardiol. 2015; 12(1): 23-29, doi: 10.11909/j. issn.1671-5411.2015.01.003, indexed in Pubmed: 25678901.

23. Li Y, Han Y, Guan S, et al. Optimal- vs. standard-antiplatelet therapy on platelet function and long-term clinical outcomes in patients with high on-treatment platelet reactivity: 2-year outcomes of the multicentre, randomized Optimal-antiPlatelet Therapy (OPT) trial. Eur Heart J Suppl. 2015; 17(suppl B): B23B31, doi: 10.1093/eurheartj/suv024.

24. Cayla G, Cuisset T, Silvain J, et al. Platelet function monitoring to adjust antiplatelet therapy in elderly patients stented for an acute coronary syndrome (ANTARCTIC): an open-label, blindedendpoint, randomised controlled superiority trial. Lancet. 2016; 388(10055): 2015-2022, doi: 10.1016/S0140-6736(16)31323-X, indexed in Pubmed: 27581531.

25. Koltowski L, Tomaniak M, Aradi D, et al. Optimal aNtiplatelet pharmacotherapy guided by bedSIDE genetic or functional TESTing in elective PCI patients: A pilot study: ONSIDE TEST pilot. Cardiol J. 2017; 24(3): 284-292, doi: 10.5603/CJ.a2017.0026, indexed in Pubmed: 28281736.

26. Breet NJ, van Werkum JW, Bouman HJ, et al. Comparison of platelet function tests in predicting clinical outcome in patients undergoing coronary stent implantation. JAMA. 2010; 303(8): 754-762, doi: 10.1001/jama.2010.181, indexed in Pubmed: 20179285.

27. Aradi D, Kirtane A, Bonello L, et al. Bleeding and stent thrombosis on P2Y12-inhibitors: collaborative analysis on the role of platelet reactivity for risk stratification after percutaneous coronary intervention. Eur Heart J. 2015; 36(27): 1762-1771, doi: 10.1093/eurheartj/ehv104, indexed in Pubmed: 25896078.

28. Collet JP, Hulot JS, Pena A, et al. Cytochrome P450 2C19 polymorphism in young patients treated with clopidogrel after myocardial infarction: a cohort study. Lancet. 2009; 373(9660): 309-317, doi: 10.1016/S0140-6736(08)61845-0, indexed in Pubmed: 19108880.

29. Simon T, Verstuyft C, Mary-Krause M, et al. Genetic determinants of response to clopidogrel and cardiovascular events. N Engl J Med. 2009; 360(4): 363-375, doi: 10.1056/NEJMoa0808227, indexed in Pubmed: 19106083.

30. Beitelshees AL, Voora D, Lewis JP. Personalized antiplatelet and anticoagulation therapy: applications and significance of pharmacogenomics. Pharmgenomics Pers Med. 2015; 8: 43-61, doi: 10.2147/PGPM.S52900, indexed in Pubmed: 25897256.

31. Campo G, Miccoli M, Tebaldi M, et al. Genetic determinants of on-clopidogrel high platelet reactivity. Platelets. 2011; 22(6): 399-407, doi: 10.3109/09537104.2011.579648, indexed in Pubmed: 21627411.

32. Shuldiner AR, O'Connell JR, Bliden KP, et al. Association of cytochrome P450 2C19 genotype with the antiplatelet effect and clinical efficacy of clopidogrel therapy. JAMA. 2009; 302(8): 849-857, doi: 10.1001/jama.2009.1232, indexed in Pubmed: 19706858.

33. Mega JL, Hochholzer W, Frelinger AL, et al. Dosing clopidogrel based on CYP2C19 genotype and the effect on platelet reactivity in patients with stable cardiovascular disease. JAMA. 2011; 306(20): 2221-2228, doi: 10.1001/jama.2011.1703, indexed in Pubmed: 22088980.

34. Sibbing D, Koch W, Gebhard D, et al. Cytochrome 2C19*17 allelic variant, platelet aggregation, bleeding events, and stent thrombosis in clopidogrel-treated patients with coronary stent placement. Circulation. 2010; 121(4): 512-518, doi: 10.1161/CIRCULATIONAHA.109.885194, indexed in Pubmed: 20083681.

35. Sangkuhl K, Klein T, Altman R. Clopidogrel pathway. Pharmacogenetics and Genomics. 2010: 1, doi: 10.1097/ fpc.0b013e3283385420.

36. Ancrenaz V, Daali Y, Fontana P, et al. Impact of genetic polymorphisms and drug-drug interactions on clopidogrel and prasugrel response variability. Curr Drug Metab. 2010; 11(8): 667-677, indexed in Pubmed: 20942779.

37. Hulot JS, Bura A, Villard E, et al. Cytochrome P450 2C19 lossof-function polymorphism is a major determinant of clopidogrel responsiveness in healthy subjects. Blood. 2006; 108(7): 2244-2247, doi: 10.1182/blood-2006-04-013052, indexed in Pubmed: 16772608.

38. Shuldiner AR, O'Connell JR, Bliden KP, et al. Association of cytochrome P450 2C19 genotype with the antiplatelet effect and clinical efficacy of clopidogrel therapy. JAMA. 2009; 302(8): 849-857, doi: 10.1001/jama.2009.1232, indexed in Pubmed: 19706858.

39. Hochholzer W, Trenk D, Fromm MF, et al. Impact of cytochrome P450 2C19 loss-of-function polymorphism and of major demographic characteristics on residual platelet function after loading 
and maintenance treatment with clopidogrel in patients undergoing elective coronary stent placement. J Am Coll Cardiol. 2010; 55(22): 2427-2434, doi: 10.1016/j.jacc.2010.02.031, indexed in Pubmed: 20510210.

40. Fontana P, James R, Barazer I, et al. Relationship between paraoxonase-1 activity, its Q192R genetic variant and clopidogrel responsiveness in the ADRIE study. J Thromb Haemost. 2011; 9(8): 1664-1666, doi: 10.1111/j.1538-7836.2011.04409.x, indexed in Pubmed: 21692977.

41. Lewis JP, Stephens SH, Horenstein RB, et al. The CYP2 $\mathrm{C} 19 * 17$ variant is not independently associated with clopidogrel response. J Thromb Haemost. 2013; 11(9): 1640-1646, doi: 10.1111/jth.12342, indexed in Pubmed: 23809542.

42. Franken $\mathrm{CC}$, Kaiser AFC, Krüger JC, et al. Cytochrome P450 2B6 and 2C9 genotype polymorphism--a possible cause of prasugrel low responsiveness. Thromb Haemost. 2013; 110(1): 131140, doi: 10.1160/TH13-01-0021, indexed in Pubmed: 23615745.

43. Cuisset T, Loosveld M, Morange PE, et al. CYP2C19*2 and *17 alleles have a significant impact on platelet response and bleeding risk in patients treated with prasugrel after acute coronary syndrome. JACC Cardiovasc Interv. 2012; 5(12): 1280-1287, doi: 10.1016/j.jcin.2012.07.015, indexed in Pubmed: 23257377.

44. Mega JL, Close SL, Wiviott SD, et al. Genetic variants in ABCB1 and CYP2C19 and cardiovascular outcomes after treatment with clopidogrel and prasugrel in the TRITON-TIMI 38 trial: a pharmacogenetic analysis. Lancet. 2010; 376(9749): 1312-1319, doi: 10.1016/S0140-6736(10)61273-1, indexed in Pubmed: 20801494.

45. Taubert D, von Beckerath N, Grimberg G, et al. Impact of P-glycoprotein on clopidogrel absorption. Clin Pharmacol Ther.
2006; 80(5): 486-501, doi: 10.1016/j.clpt.2006.07.007, indexed in Pubmed: 17112805 .

46. Price MJ, Murray SS, Angiolillo DJ, et al. Influence of genetic polymorphisms on the effect of high- and standard-dose clopidogrel after percutaneous coronary intervention: the GIFT (Genotype Information and Functional Testing) study. J Am Coll Cardiol. 2012; 59(22): 1928-1937, doi: 10.1016/j.jacc.2011.11.068, indexed in Pubmed: 22624833.

47. Storey RF, Melissa Thornton S, Lawrance R, et al. Ticagrelor yields consistent dose-dependent inhibition of ADPinduced platelet aggregation in patients with atherosclerotic disease regardless of genotypic variations in P2RY12, P2RY1, and ITGB3. Platelets. 2009; 20(5): 341-348, doi: 10.1080/09537100903075324, indexed in Pubmed: 19637098.

48. Tantry US, Bliden KP, Wei C, et al. First analysis of the relation between CYP2C19 genotype and pharmacodynamics in patients treated with ticagrelor versus clopidogrel: the ONSET/OFFSET and RESPOND genotype studies. Circ Cardiovasc Genet. 2010; 3(6): 556-566, doi: 10.1161/CIRCGENETICS.110.958561, indexed in Pubmed: 21079055.

49. Akerblom A, Eriksson N, Wallentin L, et al. PLATO Investigators. Polymorphism of the cystatin $\mathrm{C}$ gene in patients with acute coronary syndromes: Results from the PLATelet inhibition and patient Outcomes study. Am Heart J. 2014; 168(1): 96-102.e2, doi: 10.1016/j.ahj.2014.03.010, indexed in Pubmed: 24952865.

50. Varenhorst C, Eriksson N, Johansson A, et al. Ticagrelor plasma levels but not clinical outcomes are associated with transporter and metabolism enzyme genetic polymorphisms. J Am Coll Cardiol. 2014; 63(12): A25, doi: 10.1016/s0735-1097(14)60025-5. 